\title{
NIÑOS Y JOVENES EN LAS PITIUSAS DEL SIGLO XVIII
}

\author{
Jorge DEMERSON
}

Existen en la actualidad varios movimientos que tienen por finalidad esencial proteger a la infancia. El más conocido, sin duda, es la UNICEF, institución internacional que organiza cada año varias campañas para recaudar fondos en casi todos los países del mundo. Su fin es ayudar material y moralmente en los cinco continentes a la infancia desdichada. Iniciativas desinteresadas de este tipo son muy necesarias pues, a pesar de los esfuerzos de la FAO y otros organismos internacionales, más de la cuarta parte de la humanidad -unos 800 millones de hombres, mujeres y niños- no tiene siquiera lo imprescindible para sobrevivir: al pie de la letra "no tienen ni para comer". En nuestro mundo orgulloso de su progreso y su riqueza, hay zonas que padecen hambres espantosas: el Sahel, la India, el nordeste de Brasil, muchas provincias de Suramérica, especialmente en su parte andina, etc...

Esos organismos protectores del hombre y del niño, cuya creación relativamente reciente honra a nuestra época, no existían por supuesto en el siglo 18, aunque sí existían entonces, y tan apremiantes como ahora, si no más, los problemas que estas organizaciones pretenden resolver. Y lo que es más, estos problemas se planteaban no sólo a unas poblaciones de Asia, Africa o América, como ahora, sino también en los países de Europa y singularmente en España. Me propongo estudiar un aspecto muy concreto y limitado de esta cuestión, en su faceta española: el aspecto que revestía en un punto muy reducido del país: las islas Pitiusas.

Para el archipiélago pitiuso, el siglo XVIII fue una época fausta. Creció notablemente la población, puesto que Formentera, despoblada desde finales del siglo XV a consecuencia de las constantes correrías de los berberiscos que se llevaban a sus tierras, como esclavos, a los desdichados isleños, volvió a poblarse. La inmigración fue tan activa que al finalizar la centuria, la población de la isla rozaba el millar de almas. Asimismo fue fausto para Ibiza este período pues en 1782 fue agraciada la capital de la isla con el título de Ciudad y vino a ser la sede de una nueva diócesis. Estos hechos tuvieron no poca importancia para el desarrollo del archipiélago pitiuso. 
En el momento de la creación del obispado, el padrón de la población formado poco antes arrojaba un total de 15000 almas: 14.000 para Ibiza y unos 1.000 para Formentera. En Ibiza capital vivían 3.000 personas, repartiéndose los otros once mil por el campo. La economía de las islas era entonces casi exclusivamente agrícola.

Las curvas demográficas, establecidas en documentos fehacientes, demuestran que durante aquella centuria la población fue creciendo paulatinamente. Ese crecimiento moderado se explica, no por la baja cifra de los nacimientos -al contrario, éstos eran numerosos- sino por la mortalidad infantil muy elevada que mermaba considerablemente el número de los supervivientes. Todavía no poseemos estadísticas sobre este punto. Por cierto, antes de la creación del obispado en 1782, semejantes estadísticas parecen difíciles de establecer porque las Pitiusas formaban, como es sabido, una parroquia única cuya iglesia, Santa María La Mayor, hoy catedral de Ibiza, resultaba muy distante para muchos payeses, de forma que éstos dejaban a menudo de cumplir los preceptos de la Iglesia y, en particular solían enterrar a su retoños muertos sin dar parte al paborde, o cura, de aquella lejana parroquia. En cambio, a partir de 1786, es decir cuando, tras la división de las dos islas en 20 parroquias, la vida religiosa empezó a correr por cauces más racionales, los curas tenían la obligación de llevar cuidadosamente "los cinco libros", entre ellos el de bautizados y el de muertos, de modo que a partir de esta fecha resulta posible formar estadísticas bastante fidedignas. Pero queda por hacer este estudio.

Ahora bien, los libros de defunciones permiten apreciar, con sólo echar una ojeada a sus márgenes, las epidemias que azotaron las islas. Epidemias debidas al calor canicular de julio y de agosto, causa de deshidratación en las criaturas; epidemias de tercianas, cuartanas y otras enfermedades palúdicas, temidas por los adultos y que no perdonaban a los niños: epidemias de algún contagio o pestilencia, sobre todo sarampión, tos ferina y viruelas y otras plagas semejantes que penetraban fácilmente en unas islas donde prosperaba el contrabando y, si damos fe al obispo Abad, no se solía respetar la más elemental cuarentena (1). Se traducían estas calamidades en los libros de muertos de una manera muy gráfica: en las márgenes de estos libros aparecen largas retahilas de "párvulo" o de "ángel" que indican palmariamente que las víctimas de estas hecatombes eran niños de corta o muy corta edad.

Aunque, es verdad que la palabra "párvulo" podía ser engañosa. Por "párvulo", se suele designar normalmente un niño que no ha salido todavía de la pequeña infancia, o sea de menos de 6 ó 7 años. El "parvulario" era antaño esa sección de una escuela primaria que acogía a los educandos pequeños, más o menos los que ahora pueblan nuestros jardines de infancia o "kindergarten". Era pues natural que en los aranceles que estipulaban el precio de las funciones de iglesia se hubiera previsto una tarifa de entierro más barata para un párvulo que para un adulto o incluso para un adolescente. Ahora bien, movidos por la pobreza que en muchos casos no era fingida, o algunas veces por la codicia, aprovechando la circunstancia de que las partidas de defunción no mencionaban ni la edad, ni la fecha de nacimiento del finado, muchos padres ibicencos - tal vez con la complicidad comprensiva de los vicarios o curas - declaraban como "párvulo" un muerto de 13 ó 14 años. Este abuso, al parecer frecuente, queda estigmatizado 
por los primeros obispos de la diócesis, y la misma repetición de las críticas manifiesta claramente que no fue fácil de erradicar.

Otros enemigos que acechaban a la infancia pitiusa eran las consecuencias de la consanguinidad. El aislamiento casi absoluto en el que quedaron sumidas las islas a pesar de su relativa proximidad a las costas de Levante, impidió toda aportación de sangre nueva. Los ibicencos no tenían más remedio que casarse entre sí y en la mayoría de los casos dentro de su misma parroquia y con un hijo o una hija de un vecino inmediato. Eso mismo habían hecho ya sus padres, sus abuelos y tatarabuelos, de forma que todos eran primos más o menos próximos. Frecuentísimos eran los casos en que los novios tenían que pedir dispensa eclesiástica para poder pasar ante el cura. Las frecuentes diferencias, incluso la hostilidad, que existían entre los varios sectores de las islas y luego, después de 1786, entre las parroquias recién creadas, hacían más habitual y estrecha esa endogamia. No habían ideado los ibicencos, como los isleños de la Polinesia o, en general, del Pacífico, ese eficaz método de renovación de la sangre tribal que consistía en ofrecer a los navegantes que abordaban a sus costas, todas las mujeres o muchachas núbiles del clan. A pesar del ejemplo de libertad sexual que durante siglos les habían dado los musulmanes moradores de las Pitiusas; a pesar de la añoranza de las costumbres berberiscas que dormitaba en la mente de todos los que -esclavos o renegados- habían vivido en "Berbería", añoranza que late en el episodio del Cautivo del Quijote y en las comedias cervantinas de El trato de Argel y Los baños de Argel, los ibicencos no imitaron a sus vecinos y constantes adversarios del Norte de Africa. Las campesinas del interior no alternaban con los navegantes que aportaban en Eivissa o en Portmany; en cambio en el Barrio de la Marina se concluían no pocos matrimonios con peninsulares, catalanes o valencianos, y con palmesanos y hasta canarios, incluso con algún que otro francés o italiano (2).

El hecho es que, hija de la insularidad, imperaba en estas islas la consanguinidad que hacía en ellas sus habituales estragos, sumando e incluso multiplicando geométricamente las taras de las dos sangres vecinas que se mezclaban una vez más. Las malformaciones congenitales, los casos de imbecilidad, idiotez y mongolismo eran proporcionalmente más numerosos en ellas que en el resto de España como es notorio y lo ha señalado ya en sus escritos el Historiador de Ibiza, don Isidoro Macabich. La consanguinidad contribuía pues en no poca medida a disminuir el número de ibicencos útiles que nacían cada año.

Contribuian a mantener muy alta la mortalidad infantil el mal estado general de las islas, la falta frecuente de higiene y en particular la carencia de las precauciones más elementales en el uso de las aguas. Sabemos ahora, pero poca gente sospechaba hace dos siglos, que el agua podía ser el vehículo de muchas enfermedades, especialmente de las que llamamos ahora bacterianas o víricas. Adelantándose a su tiempo, el primer obispo de lbiza, don Manuel Abad y Lasierra, hombre ilustrado y reflexivo, que se interesaba por la salvación eterna de sus feligreses pero también por su salud física, denunciaba con terca insistencia en la suciedad y mal uso de las aguas la causa probable de las muchas dolencias esporádicas o epidémicas que afectaban al pueblo: "Mucha parte de las enfermedades crónicas que se padecen -tercianas y fiebres-pro- 
vienen del abandono general y mal uso del agua, juntamente con los cenagales, escombros y pantanos corrompidos que nos rodean, los cuales sobre ser contra la salud, ofenden a un pueblo civil".

Un problema urgente cuya importancia recalcan las autoridades es el de los niños abandonados. En realidad, se trata de una cuestión compleja y que ofrece varias facetas. En primer lugar, existe en Ibiza como en todas partes el problema de los recién nacidos abandonados por una madre soltera, que no se atreve a afrontar el qué dirán y la censura social, muy fuerte en una población limitada, cerrada y tradicionalista como la ibicenca; o también de los niños legítimos, abandonados en período de penuria, si no de hambre, por unos padres indigentes, incapaces de alimentar una boca más. Es cierto que existía en la capital de la isla una "Inclusa" que recogía los niños abandonados de toda la isla y de Formentera. No sabemos cuál era y cómo funcionaba el sistema de recogida de los expósitos antes de la creación del obispado. Pero después de la erección de las parroquias rurales, se dan casos de niños abandonados en los "porxus" de las iglesias foráneas; el cura solía confiarlos a alguna de sus feligresas hasta que se podían llevar a la ciudad. Sin duda en el transporte, y singularmente durante los grandes calores del verano, algunos de estos inocentes perecían en el trayecto. No tenemos estadísticas ni del promedio de expósitos que se recogían cada año, ni de los que morían. Sólo podemos suponer que dada la benignidad general del clima de las islas, la mortalidad infantil insular no era tan elevada como en la península. Conocida es la cifra espantosa que apunta Domínguez Ortiz a propósito de la Inclusa de Jaén: en cinco años ingresaron en ese establecimiento 889 niños y sólo sobrevivieron 6 (3). Lo cierto es que el funcionamiento de la Inclusa de Ibiza no fue del agrado del obispo de la diócesis, doctor Abad y Lasierra. En efecto, en una época en que no se había difundido aún el uso del biberón, y por lo tanto los mamones eran literalmente niños de teta, el patrono de la Inclusa a quien incumbía el cuidado de escoger a las nodrizas, velar sobre su aseo y por lo tanto tratar constantemente con ellas, era un sacerdote. Lo que explica sobre todo los reparos del obispo es que esas nodrizas no solían ser dechados de virtud, desinterés y pudor; al parecer se reclutaban frecuentemente entre las prostitutas y muchas de ellas no vacilaban en abandonar a sus propios retoños, ingresándolos en la Inclusa como expósitos, con el fin de cobrar más dinero, al poder cuidar de uno o dos niños de pecho más.

En los libros de bautismo de las parroquias ibicencas se puede rastrear la pista de algún que otro expósito: tal vez con el inconsciente deseo de aplacar los rigores de un Fatum malévolo, se solía dar a los expósitos el nombre fetiche de "Ventura", siguiendo en esto una costumbre que no era privativa de las Pitiusas.

Ignoramos cuál era la suerte de los incluseros una vez destetados. Sin duda se les confiaba a alguna familia que cuidaba de ellos por un modesto estipendio. No parece haber sido la Inclusa un establecimiento de educación y enseñanza, ni por lo visto tenía personal preparado para estos menesteres. Sea porque los padres adoptivos no podían vigilarlos, sea porque, como la cabra, tiraban al monte, sea por cualquier otro motivo, estos chavales pronto se encontraban en la calle o por los caminos, donde se reunían con otros compañeros, huérfanos o expósitos como ellos, hijjos legítimos o adoptivos 
de los campesinos de los contornos. Estos niños, al igual de lo que pasa hoy día en ciertas ciudades-dormitorio, satélites de las grandes capitales, para luchar contra el ocio y el aburrimiento, formaban pandillas más o menos numerosas, que ya en la ciudad, ya en las zonas rústicas se entregaban a toda clase de picardías y exacciones, robando fruta en los puestos de los vendedores o saqueando huertas en despoblado. Había llegado a ser tan serio y apremiante el problema que en la sesión fundacional de la Junta General convocada por el Obispo y el Gobernador para reorganizar el gobierno de las islas, todos los vocales declararon de consuno que ésta era la primera cuestión a resolver y que convenía recoger a esos niños que vagueaban por la isla en un Asilo en el cual se les alojaría, cuidaría y enseñaría las primeras letras y un oficio sencillo, de los muchos que faltaban en la isla, para que pudieran ganarse honradamente la vida.

Esa preocupación por instruir a la juventud era digna de encomio, pues la docencia en Ibiza hacia finales del siglo XVIII se reducía a muy poca cosa. Si damos fe al primer obispo, no existía en la capital pitiusa, ni a fortiori en lo demás de la isla, escuela pública alguna. Sí había clases de pago para la gente adinerada y los comerciantes acomodados. En beneficio de los demás, gente insolvente, los dominicos se habían comprometido a impartir una enseñanza elemental, sin duda gratuita, de la cual se beneficiaba un corto número de alumnos. Por cierto, había en la Ciudad una clase alta bastante ilustrada: abogados, escribanos, procuradores, canónigos y beneficiados manejaban, además del castellano y del ibicenco, el latín. Asimismo sabían leer y escribir los patrones de barco, los médicos y farmaceúticos y muchos comerciantes del barrio de la Marina. Pero en el campo, donde vivían las cuatro quintas partes de la población, todos eran analfabetos.

Tampoco existía antes de 1786 formación religiosa coherente, ni clases de catecismo. Nadie se preocupaba por elevar a los jóvenes encima de la vida material harto mezquina que les había tocado llevar. Nadie tampoco cuidaba de enseñar un oficio a esos niños que se pasaban los días en la más completa ociosidad. La razón de la inexistencia de cualquier aprendizaje era muy sencilla: no había prácticamente artesanos en la Isla, y los útiles más corrientes, los objetos más comunes como las tejas, los platos, incluso los ladrillos, los sombreros, las cerraduras, etc., todo se importaba de Valencia o de Mallorca. Era casi nula la industria pitiusa, y la adquisición de objetos manufacturados fuera de la isla resultaba muy onerosa, pues los gastos de transporte se añadían al precio del género.

A los niños, les pasaba lo que a los muchachos: misma crasa ignorancia, misma ociosidad e igual carencia de ocupación útil y remuneradora. En el campo, se criaban los varones junto a las faldas de sus madres; luego, pasaban bajo la autoridad directa del padre; pero éste, ufano de servir en las milicias urbanas y llevar armas de fuego, estaba a menudo ausente y, cuando volvía a la finca, trabajaba poco en las faenas agrícolas que, por haber sido desempeñadas durante siglos por esclavos moros, quedaban desprestigiadas. De forma que sin arrimo ni ocupación, el chico se iba a vaguear con los otros muchachos de su edad. El obispo Abad, hombre muy moderado, para vituperar a esos jóvenes ibicencos, no halla fórmulas bastante acerbas. Así las cosas, se com- 
prende que la Junta General haya considerado unánime como de primera urgencia la organización de un asilo.

En Galicia, tierra pobre como lbiza, y donde cada cual tenía que ganarse cuanto antes el pan que comía, los jóvenes de ambos sexos "entraban a servir" en edad muy temprana, si admitimos que las ficciones literarias de Valle-Inclán reflejan en alguna medida la realidad humana y social de su tierra: a los nueve años, a veces a los siere, como el paje Florisel de las Escenas románticas, como el muchacho anónimo que se "acomoda" de Lazarillo con el ciego Electos, como Adega en el Pazo de Brandeso en Flor de Santidad, como otros en la Sonata de Otoño. Estos niños servían "por el yantar y el vestir", lo que les permitía salir adelante. Pero en Ibiza, el niño pobre no tenía el mismo recurso que su primo gallego, porque en la isla no había el equivalente de la nobleza rumbosa y generosa de las rías. Siendo en las Pitiusas muy corto el número de personas pudientes, escaseaban trágicamente los empleos de esta clase.

Con todo, aunque en ambiente totalmente distinto, algunos adolescentes ibicencos empezaban a servir muy jóvenes: las niñas guardaban los rebaños de ovejas, los varones servían en las labores del campo. Pero el muchacho estaba más en contacto con el ama que con el amo. Mientras éste vigilaba la costa, la mujer, abrumada de trabajo, lo hacía todo en la modesta choza. La lista de sus "labores" era interminable. Cuidaba de la limpieza de la casa, de lavar, guisar, tejer, hilar, remendar, cuando no fuera cortar y coser la ropa de toda la familia. Y además, parir una vez al año y criar a los retoños. Amén de todo esto, cargaba con la responsabilidad de las faenas agrícolas, la alimentación de las aves de corral, del cerdo, etc. La mujer ibicenca, al decir de los testigos que la vieron vivir -malvivir- en el siglo XVIII, se mataba trabajando (4).

Un niño, o un joven espabilado podía ser para ella un colaborador eficaz y un alivio apreciable. Fuera de estas ocupaciones rústicas, sólo conocemos una que fuese de pane lucrando y en que se podía emplear un muchacho: la de monaguillo. Éste cobraba un sueldo modesto, pero fijado con arreglo a un arancel oficial.

No era muy alegre la vida de los jóvenes ibicencos. Las diversiones eran muy contadas. Las más usuales eran las veladas, que se celebraban por turno en casa de los vecinos o en la casa propia. En esas reuniones se comentaban las noticias del "barrio" o las informaciones que con mucho retraso se trasmitian oralmente sobre las guerras, las epidemias, el gobiemo, se relataban leyendas o historias ya en su forma tradicional de romances o poesías asonantadas que las viejas, haciendo memoria, iban recitando con la misma voz atiplada con que las decoraban allá en sus mocedades, y marcando fuertemente la cadencia y asonancia de los versos. Otras veces, un repentista lucia sus habilidades relatando o inventando un cuento, y las buenas gentes coreaban gustosas las alusiones a los conocidos. En ocasiones, se daba la palabra a un anciano poeta payés, -auténtico sabio para los demás, pues sabía leer y escribir-quien, con voz estentórea, declamaba sus composiciones, a menudo religiosas: "misteris, miracles, oracions" que tenía copiadas en un "cuadernet". Este cuademito le acompañaba a todas partes, pero nunca lo abría pues se sabía de memoria todas esas poesías. Otras noches, el poeta se convertía en músico, en "tocador", y con el tamboril ibicenco apoyado en el 
muslo izquierdo y sujeto por el codo del mismo lado, con la flauta en la siniestra mano y el palito en la diestra, iniciaba su concierto. En circunstancias muy solemnes, el músico tocaba a duo con su hijo, su yerno o algún "net", o sea "nieto". Si se da el caso, si hay entre los concurrentes algún "cantaor" la fiesta de Euterpe es completa: tras una obertura a cargo del tocador, el cantador, cerrados los ojos, empieza a relatar los tristes amoríos de alguna payesa galana, o el combate naval que los atrevidos corsarios ibicencos ganaron a los berberiscos o ingleses, en que apresaron un barco enemigo más grande y fuerte que el jabeque que los venció. $\mathrm{Y}$ al final de cada estrofa, invariablemente, suena el extraño "ay, ay, ay!", herencia inconfundible que los moros, al abandonar la isla, legaron a los tataranietos de sus conquistadores. En las pausas del concierto, mientras cascan las almendras o mondan las naranjas que han traído, los concurrentes cambian impresiones, bromean, se echan pullas, todo ello, naturalmente en lenguaje vernáculo, pues menos la gente de la capital, que saben y usan el castellano, el ibicenco es el único idioma que se maneja en la payesía.

Todas las fiestas en las que participaban los niños o jóvenes ibicencos tenían con poca diferencia los mismos ingredientes, a los que hay que añadir por supuesto unas copiosas comidas, cuando de festejos familiares como de bautizos, o bodas se trataba. En esas reuniones, sólo después de actuar el cantaor se permitía a los hombres liar y encender unos puros o cigarrillos de "pota", el nauseabundo tabaco local que cada uno clandestinamente cultivaba en algún rincón de su huerto: el humo hediondo que despedía este tabaco fuerte y bruto hacía lagrimear los ojos y toser a los niños y a las "dones".

Las fiestas locales, en honor de Santa María de las Nieves o de San Ciriaco, vinculadas al recuerdo de la reconquista de las islas a los moros el 8 de agosto de 1235, o las que se celebraban en honor del santo patrono de cada parroquia, tenían un aliciente más. Eran más movidas, permitían un mayor o mejor esparcimiento. Tras las tradicionales funciones de iglesia, misa solemne, desfiles y disparos de las milicias, procesión, vísperas, los niños -y los mayores- podían entregarse al solaz de la verbena y sus múltiples juegos: cucaña, carreras diversas, de velocidad, de saco, de trabas, concursos de saltos, pruebas de fuerza o de habilidad, como clavar un clavo de hierro sin templar en un leño de roble o de olivo; juegos de naipes, de bochas, de barras, de anillos, de pesca... Y los vencedores, risueña y ruborizada la cara por el placer, pasaban ufanos con la botella de vino payés o el pollo patiatado que habían ganado. Pero para los adolescentes, lo más saliente de la jornada era el baile. El baile con que soñaban desde hacía semanas; el baile en que podían acercarse a las "al.lotas", las muchachas, sin suscitar la inquina de los mayores.

Esas ocasiones de regocijo social y público eran contadas. La vida cotidiana solía transcurrir monótona, rutinaria e insípida. Esa monotonía no casa con la fantasía, el dinamismo, el empuje vital de la infancia y de la adolescencia. Entre los hombres ausentes y las mujeres atareadísimas, los jóvenes, abandonados a sí mismos, disponían indudablemente de mucha libertad. Una libertad que la ausencia de consejos familiares por una parte, y la ociosidad siempre mala consejera por otra, hacían harto peligrosa. La juventud ibicenca, singularmente la del campo, solía iniciar tempranamente una 
vida sexual activa, o porque seguía las pulsiones de su temperamento, o porque -y ello no era infrecuente- los propios padres la llevaban pronto al matrimonio.

Las pulsiones de su temperamento: no encontraban barreras o freno ni en su educación, ni en sus ocupaciones. Al llegar a Ibiza en 1784, el primer obispo de las Pitiusas, D. Manuel Abad y Lasierra, nota, como queda dicho, que los jóvenes no reciben ninguna clase de instrucción ni de educación, y recalca en particular que no se les enseña el catecismo ni las más sencillas reglas de la moral natural ni de la cristiana; en una palabra que "se crían con poca diferencia de las fieras". El monje aragonés no ocultaba su opinión: los adolescentes ibicencos eran ni más ni menos que unos salvajes. La única tarea que se les podía y solía confiar a los pequeños campesinos era apacentar el ganado, las pocas ovejas y algunas cabras que poseía cada familia. Así pasaban largas horas, tal vez el día entero, en despoblado lejos de toda vigilancia, paterna o materna. Frecuentemente, por casualidad o por voluntad, un chico y una chica se reunían conduciendo sus respectivos rebaños a la misma apartada dehesa, como antaño hacían Salicio y Nemoroso en las Eglogas de Garcilaso. Y en su ruda inocencia, esos pequeños salvajes reinventaban sin saberlo los juegos y travesuras, los requiebros y caricias, los amores infantiles -o adolescentes- de Dafnis y Cloé.

Las causas matrimoniales conservadas en el Archivo de la Curia eclesiástica de Ibiza evocan a menudo esos episodios amorosos de la vida pastoral de la isla. El campo, y más aún el campo ibicenco, donde siempre el pinar cerca una "feixa" cultivada o linda con ella; donde las paredes de piedra seca limitan los bancales escalonados en la falda de los "pujols"; donde el paisaje boscoso está sembrado de setos, vergeles o manchas de árboles, tiene como Argos, cien ojos con que espía continuamente cuanto ocurre en esa aparente soledad absoluta. Por ejemplo, en medio de las tinieblas cerradas de una noche sin luna, un joven rapta a su prometida consentidora y se la lleva en las ancas a otro sitio de la isla. Los enamorados creen que nadie reparó en ellos. Pero durante la vista del pleito incoado por los padres de la muchacha en la Curia eclesiásti$\mathrm{ca}$, se presentaron varios testigos que habían presenciado el rapto, reconocido a los protagonistas y que pudieron dar un sinfín de detalles concretos, hasta el color exacto del caballo.

Otras veces el encuentro carecía de todo halo romántico o caballeresco. Cierto día de bochorno incomodados por el calor de agosto, un pastorcito y una payesita se colaron por debajo de una "mata", o sea una mata de lentisco, especie que en las Baleares puede alcanzar dimensiones impresionantes. Pero entonces otros ardores sustituyeron los del sol, se enardeció la sangre de los zagales y, como en el conocido refrán de la lumbre y la estopa, "vino el diablo y sopló". Esos excesos fueron aireados en la Curia y se supo que la niña no era tan inocente como permitían esperarlo sus pocos años. Testigos hubo que vinieron a afirmar que ella acostumbraba a ir con cualquiera. Y todos echaron la culpa a los padres que no vigilaban a sus hijas como Dios manda.

En otras ocasiones, la muchacha no consentía, pero había de ceder a la fuerza. Además de raptos, la Curia había de conocer de violaciones. Cierta huérfana de quince abriles vivía con sus cuatro hermanos en el norte de la isla. Pero éstos se ausentaron 
por un mes a las labores de las Salinas al sur de Ibiza. Quedó pues sola la niña para guardar la casa familiar algo aislada. Una noche, consiguiendo romper un postigo, se metió un mozo de la vecindad en el cuarto de la joven. Ella resistió cuanto pudo, pero quedó vencida; rogó y suplicó que la dejara, mas en balde. Total que el muchacho "hizo de ella cuanto quiso" según fórmula frecuente en los autos. Hasta aquí, se trata de una violación caracterizada. En cambio, el vocablo no parece tan adecuado a lo que pasó a continuación: volvió varias veces el "violador" y la muchacha le acogió tan sumisa como había quedado tras su derrota en buena lid el primer día. De forma que ocurrió lo que era de esperar: ella quedó "grávida". El Vicario General mandó prender y encarcelar al autor de este "exceso", quien se negó testarudamente a reconocer los hechos. Nació la criatura, y cuatro años más tarde, el padre seguía encarcelado, y la muchacha tan soltera como antes de los acontecimientos.

Es indudable que los jóvenes ibicencos gozaban en el siglo XVIII de una libertad de movimientos casi total y escapan a menudo a la autoridad de sus padres, autoridad teóricamente absoluta, y a su vigilancia, causando así verdaderos escándalos. En una causa matrimonial, un joven desairado se venga de la doncella que le había dado calabazas contando que ella no tenía verguenza, que a los doce años se paseaba por la capital de la isla en un carro, encaramada en un montón de melones y sin ocultar de su cuerpo aquello que debiera tapar la falda. Asimismo, le acusa de haberse bañado desnuda en medio de un grupo de chavales en la playa de Sa Peña, al lado del puerto de Ibiza.

Asombroso en una sociedad mojigata, el hecho no es increible, como lo prueba el testimonio de una "dona" recogido hace unos años. Esa mujer ibicenca que tendrá ahora unos 60 años nació por el 1930. Natural y vecina del norte de la isla, cerca de San Vicente, contaba que, cuando tenía entre 12 y 15 años, es decir a raíz de la guerra civil o poco después - en todo caso, mucho antes de la ola turística de los años 60- solía en verano con otros jóvenes ir a pasar de vez en cuando un día en la playa. Chicos y chicas, doce o quince en total, salían temprano con su merienda para la cala de N..., la tercera o cuarta al norte de la de San Vicente, lugar solitario por ser de muy difícil acceso: la cala está adosada a una colina muy pina -como aquella en que está ubicada la cueva de Es Cuyeram- que había que subir andando a gatas para llegar a la cumbre. El único acceso normal a dicha cala era por barco.

Una vez alcanzado su destino, los componentes de la pandilla quitándose toda la ropa que llevaban encima, se quedaban "en cuní", o sea en pelota y se tiraban al agua. Después de nadar un buen rato, se tumbaban en la arena y en las rocas a tomar el sol. Pronto, un chico provocaba a la lucha a alguna al.lota, imitado en seguida por otros. Empezaban entonces unas carreras locas, persecuciones entrecruzadas puntuadas por los gritos agudos de las perseguidas asustadas. Una zancadilla traicionera echaba al suelo la ninfa. Entonces de pellizcos en cosquillas, de mordiscos en carantoñas, de abrazos en cuerpo a cuerpo, se trababan unas lides que hubiera requerido, según dijo el poeta "campos de pluma", como palestra. "Ama a tu próximo" clamaba desde el púlpito el Sr. Vicario, y paralelamente decretaba la separación de los sexos en el templo, asignando la parte derecha de la nave a las doncellas y la izquierda a los al.lots. En la 
cala cercana al santuario de Tanit, sólo se acordaban los jóvenes del primer mandamiento del Sr. Vicario. Así, concluía la buena señora, cuando por los años 1965 los padres de familia ibicencos en la polémica que publicaba el Diario de Ibiza achacaban a los hippies la libertad de costumbres -"Make love, not war!"- que empezaba a cundir abiertamente entre los jóvenes autóctonos, se equivocaban totalmente: no conocían, o no querían reconocer lo que pasaba en Sa Roqueta mucho antes de romper en sus doradas playas la primera ola turística.

De hecho, ya en el siglo XVIII y probablemente antes también, había en la Isla Blanca una gran anarquía sexual. Revelan los libros parroquiales que se celebraban muchos casamientos apresurados, de cónyuges casi niños -de 13, 14 ó 15 años-y se registraban muchos nacimientos irregulares, que a veces se regularizaban, otras no. De modo que los frutos de esos amores casi infantiles iban a parar, en el mejor de los casos, en la Inclusa de la capital insular. Los mismos libros parroquiales manifiestan más o menos claramente que esa anarquía sexual existía en todos los niveles: al lado de matrimonios regulares, que eran con todo la mayoría, se daban casos de concubinato, de poligamia, de separación de casados, cuyo número se nos antoja sorprendente en una isla de $\tan$ reducidas dimensiones. Sin embargo estos casos eran lo suficientemente numerosos como para llamar la atención de las autoridades eclesiásticas, y motivar por parte de ellas ciertas medidas o providencias drásticas.

Si bien ciertos jóvenes ibicencos, burlando la vigilancia familiar, iniciaban antes de tiempo una actividad sexual que los hacía entrar, aunque inmaturos, en el mundo de los adultos, también es cierto que no pocas veces los propios padres, por motivos egoístas o interesados, provocaban tempranamente en sus hijos, en sus hijas sobre todo, este cambio de estado.

Solían ser prolíficos los matrimonios ibicencos del siglo XVII, muchos testimoaios dan fe de ello. No era infrecuente que las mujeres pariesen una vez cada año y medio y, si no se daban epidemias mortíferas, no era excepcional que alrededor de la mesa familiar se agruparan 10612 personas entre padres e hijos. Hallar el pan de cada día para tantas bocas suponía muchos y constantes esfuerzos. De manera que los padres procuraban casar lo antes posible a sus hijas. En las Causas Matrimoniales, muchas madres, cuando sus hijas llegan a ser núbiles, generalmente cuando cumplen los 12 años, empiezan a invitar a los muchachos, los al.lots, a frecuentar su casa.

Sabido es que en Ibiza, para elegir prometido -no se empleaba la palabra "novio"existía una verdadera institución llamada "festeig". A la salida de la misa dominical, por ejemplo, se hacía cundir la voz de que tal doncella estaba dispuesta a casarse y que se la podía "festejar", es decir cortejar: la familia recibiría a los pretendientes un día de entresemana y los domingos, de las 8 de la noche en adelante. Poco antes de las 8 , llegaba el primer candidato y detrás de la puerta, silbaba. Entonces la joven subía a su cuarto a mudarse y ponerse su traje dominguero. Mientras tanto los padres acogían a los pretendientes que se instalaban en el "porxo", la sala de estar, o la "cuina", la cocina, ya sea en el poyo, hombro con hombro, o en un banco arrimado a la pared, ya sea alrededor de la mesa familiar donde podían jugar a los naipes. Mediante discusión o 
sorteo, los pretendientes se ponían de acuerdo sobre el orden en que pasarían, siendo el lugar más cotizado el último pues el que lo sacaba podía tal vez quedarse hasta muy entrada la noche.

Al llegarle el turno, el muchacho se acerca a la al.lota, sentada aparte, y con otra silla junto a la suya. Se instala en el asiento libre, dando la espalda a sus compañeros, apoyado el pie en el barrote de la silla de ella, el codo sobre la rodilla y la mejilla en la mano. Así puede hablar bajito con ella, durante un cuarto de hora o 20 minutos (según el número de pretendientes). Mientras tanto, los que esperan charlan, juegan a las cartas con los padres en el otro extremo de la habitación. Si el galanteador pasa del tiempo que se le ha señalado, sus compañeros le echan una china a la espalda. Entonces, se despide de la chica, sale y luego puede volver a entrar para seguir jugando y velando con los demás.

Estos manejos podían proseguirse durante semanas o meses, hasta que la moza casadera se decidía por uno de sus admiradores o que sus padres decidieran por ella. Pues es evidente que los padres intervenían en la elección y a veces no había festeig, o sólo un simulacro de festeig, y finalmente la niña salía de la iglesia del brazo de un hombre rico o de algún viejo amigo de su padre, que le quintuplicaba la edad, sin que pudiera hablar el corazón. En muchos casos, la joven se preciaba de "hacer el gusto de sus padres". Aparte, teóricamente, no era el festeig una institución mala o inepta. Permitía a la joven elegir entre todos sus pretendientes. Pero, haciendo caso omiso de la intromisión parental, que arreglaban el casamiento, como pasaba entonces en todos los estamentos de todos los países de Europa, el festeig entrañaba grandes peligros. Los jóvenes ibicencos, cuyas mentes rudas y orgullosas no habían sido pulidas por la cultura y la religión, consideraban como una afrenta el ser rechazados. No se vengaban en la rapaza, sino en el que les había sido preferido. Y como esos muchachos, a imitación de sus señores padres, llevaban constantemente, incluso dentro de la iglesia y en los bailes, no sólo armas blancas, navajas o puñales, sino también armas de fuego, y concretamente pistolas, no era infrecuente que el triunfador de estos extraños torneos fuese encontrado al amanecer, en el camino que llevaba a su casa, dentro de un pinar o entre las paredes de piedra seca de un camino hondo, con una bala en el pecho. El festeig causó, no cabe dudarlo, muchas muertes. Y no hace mucho un viejo payés me contó que se halló involucrado mucho más de medio siglo ha, en un caso de éstos en que la víctima fue un hermano suyo. El honor de la familia le obligaba a vengar con otra muerte la de su "germà", y sólo las súplicas de su madre, a quien adoraba, fueron capaces de hacerle desistir de la "vendetta" que él creía su deber ineludible. Por eso, a fines del siglo XIX e incluso a principios de éste, los obispos y los curas de las Pitiusas, a los que se unieron las autoridades civiles, denunciaron los estragos que causaba el festeig y consiguieron erradicar esa tradición tan venerable como arraigada.

Señalaba sin duda esa prchibición el final de una época para las Pitiusas. Una época que no dejaba de tener su interés y sus encantos. La población de estas islas mediterráneas, en su mayor parte campesina, pero con una importante minoría de pescadores y marineros, llevaba una vida próxima a la naturaleza, a las estaciones, al calendario y al mar. Vida dura, ruda, difícil, a menudo espartana y pobre. Una vida en que predomi- 
naba el trabajo, jalonada de períodos de sequía y de hambre, y en la que se daban libre curso el amor, la envidia, el odio, la violencia, a veces la muerte. Una vida bastante primitiva, que transcurría a nivel del suelo, muy cerca de la gleba, entre los cereales y las habas, las ovejas, el cerdo y las gallinas, una vida sencilla y algo monótona en la cual de vez en cuando se encendía la llamarada de la pasión. Vida casi elemental, con sus emociones ingenuas, sus alegrías y sus tristezas cotidianas y de tarde en tarde una mirada hacia arriba, hacia el cielo, hacia Dios con motivo de uno de los acontecimientos que constituyen hitos en la historia de una familia: el bautismo de un hijo, el casamiento de una hija, la muerte del abuelo o de un párvulo.

Una vida casi bíblica, patriarcal, que transcurría bajo el poder omnipotente del paterfamilias, quien ejercía su autoridad absoluta sobre los varones hasta los 21 años, hasta los 25 sobre las hembras. Antes de estas edades, no podían los hijos casarse sin el consentimiento de los padres, salvo contadas excepciones en que el Asesor Jurídico del Gobernador Político y Militar de la isla, representante del poder Real en cuestiones jurídicas, podía neutralizar la patria potestas y conceder a los amartelados prometidos el consentimiento que les negaban sus padres.

Frente a la autoridad parental se erguía otra, más fuerte aún que la autoridad Real en ciertos aspectos: la de la Iglesia, concretamente la del Provisor o Juez de la Curia eclesiástica, a quien en los Autos Matrimoniales pertenecía la última decisión. Y si, una vez celebrados ante testigos los esponsales en que dos jóvenes se daban mutuamente palabra de futuro matrimonio, con repromisión y tradición de arras, lo cual constituía un compromiso teóricamente ineludible, si pues uno de los prometidos se negaba al cumplimiento de la palabra dada, el Provisor eclesiástico, o el Vicario General que en ciertas circunstancias o períodos asumía las responsabilidades de aquél, podía mandar a petición de la otra parte que se consideraba vulnerada en sus derechos, la encarcelación del mozo en las Reales cárceles o el secuestro, también llamado "depósito", de la doncella recalcitrante en casa de una persona de reconocida solvencia moral, hasta que quedase instruido y sentenciado el caso, lo que a veces, entre juicio, apelación y dilaciones de todo tipo, podía exigir varios años. Pero con las Causas matrimoniales, entramos en otro campo, sumamente interesante por cierto, pero que por su complejidad, es acreedor a un estudio particular y detallado.

\section{NOTAS.}

1) Véase el estudio pormenorizado, hecho a partir de los libros parroquiales, de Paula de Demerson, "Una parroquia ibicenca. la de San Mateo, estudio sociológico", en Anales de Historia Contemporánea de la Universidad de Granada, 19 págs.

2) Véase el caso del soldado francés Santiago Chastain, que a mediados del siglo XVIII se 
afincó en Ibiza donde se casó, y llegó a ser cónsul de Francia y Tesorero del Ayuntamiento. P. y J. Demerson, "Santiago Chastain, cónsul de Francia en Ibiza", Cuadernos de Investigación histórica, Madrid, F.U.E., de próxima aparición.

3) Acerca de las condiciones de vida y mortalidad de los incluseros de Madrid, véase Paula de Demerson, María Francisca de Sales Portocarrero, Condesa del Montijo: una figura de la Ilustración, Madrid, Editora Nacional, 1975, 433 págs. (2 ${ }^{\underline{a}}$ parte, cpit. XI y XII).

4) Sobre la condición de las mujeres ibicencas, véase Jorge Demerson, Ibiza y su primer Obispo, D. Manuel Abad y Lasierra, Madrid, F.U.E., 1980, págs. 314 y 328. 